\title{
Archaelogical Studies at the Karatau Tumulus Burial Grounds
}

\author{
Sagynbay Serykbaevych Murgabayev ${ }^{1}$, Mels Maratovich Bakhtybayev ${ }^{1}$, Lazzat Jumagulovna Maldybekova ${ }^{1}$ \& \\ Sayden Joldasbayevich Joldasbayev ${ }^{1}$ \\ ${ }^{1}$ International Kazakh-Turkish University named Khoja Ahmet Yasawi, Republic of Kazakhstan. \\ Correspondence: Mels Maratovich Bakhtybayev, B. Sattarkhanov street, 29, Turkestan, 161200, Republic of \\ Kazakhstan. E-mail: melsb@mail.ru
}

Received: December 26, 2014 Accepted: March 25, 2015 Online Published: May 22, 2015

doi:10.5539/ass.v11n14p287 URL: http://dx.doi.org/10.5539/ass.v11n14p287

\begin{abstract}
The Karatau team of the Syganak archaeological expedition of the Research Centre of Archaeology of the International Kazakh-Turkish University named Khoja Ahmed Yasawi hold the exploration works along the lower and middle reaches of Kyzylata and Biresek rivers in 2012 field season. In the course of the study the burial grounds Kyzylata I, Kyzylata II, Biresek I and a single tumulus Biresek II were excavated. The aim of the study is to obtain new data on early medieval cultures, identifying features of the evolution and trends in the overall development of culture and the reconstruction of obsequies and philosophical foundations of ancient tribes. The study was funded by the Committee of Science of the Ministry of Education and Science of the Republic of Kazakhstan in the framework of the budget program 055 "Research and / or scientific and technical activities", sub-programme 101 "Grant funding for research studies" by priority: "The intellectual potential of the country."
\end{abstract}

Keywords: Tumulus, burial mound, burial chamber, dromos, burial ground

\section{Introduction}

The Karatau team of Syganak archaeological expedition of the Research Centre of Archaeology of the International Kazakh-Turkish University named Khoja Ahmed Yasawi hold the exploration works on 4 tumuluses of the burial ground Kyzylata I (tumulus no. 4-7) on one tumulus of the burial ground Kyzylata II (tumulus no. 1), on two tumuluses of the burial ground Biresek I (tumulus no. 5, 12) and on a single tumulus Biresek II in 2012 field season.

\section{Techniques}

The study of tumuluses was carried out taking into account the methodological experience gained in studying similar monuments. Only the inner part of the burial chamber and dromos structures were exposed to clearing. The external shell of the structure, including the collapse of the structure, as well as the structure breakdown and the walling of inner surfaces of the burial chamber walls and dromos were subjected to the drawing. Most often the highest point of the tumulus structure was taken as a conditional " $0 "$ ". Given the fact that most tumuluses are located on slopes with a significant incline, the height of the tumulus was measured from the lowest point of the burial chamber, corresponding to the level of the bed rock of the tumulus structure.

\section{Results}

Kyzylata I burial ground is situated in the Turkestan, region of the South Kazakhstan, $17 \mathrm{~km}$ north-northwest of the Kentau city, in the valley of Kyzylata mountain stream. The burial ground was discovered in 2004 by the Turan archaeological expedition of the Research Centre of Archaeology of the International Kazakh-Turkish University named Khoja Ahmed Yasawi (Report, 2005).

In the course of studies on the monument in 2004 the tumuluses and burial mounds located on both banks of the Kyzylata River were included in the burial ground. In the study of 2012 we divided the tumulus burial ground into two separate monuments - the tumulus burial ground Kyzylata I located on the left bank of the river and the burial ground Kyzylata II located on the right bank of the river (Report, 2012).

The tumuluses of the burial ground Kyzylata I are chained from north to south, stretching along the left bank of the Kyzylata River. The beginning of the tumulus chain is located $60 \mathrm{~m}$ north of the Balakorgan fortress, and it ends $2.5 \mathrm{~km}$ to the north of it. The majority of tulumuses are located on the top of the ridge, delimiting from east 
a narrow valley of the Kyzylata River that lies at the highest point of the pass and only tumulus 1 is located in the bottomland on the bank of the river. The average distance between tumuluses is $150 \mathrm{~m}$. A total number of 17 tulumuses of different diameter and height are recorded in the burial ground.

Tumulus 4 is located on the top of the ridge bounding from east the Valley of the Kyzylata River, at a distance of $460 \mathrm{~m}$ north of the Balakorgan fortress. The tumulus consists of two parts: the tumulus structure itself, i.e. embankment and the outer ring, delimiting the tumulus pad along the entire perimeter. The tumulus is built of stones of medium and large sizes (from $0.25 \times 0.1 \mathrm{~m}$ to $1.1 \times 0.9 \mathrm{~m}$ ). Rock broad stone was mainly used in the walling. The sizes of the tumulus itself, taking into account the collapse of the structure, are $8 \times 9 \mathrm{~m}$. The height of the remained part from the floor level of the burial chamber is $1.35 \mathrm{~m}$. Diameter of the ring at the perimeter (excluding the collapse of the ring) is $13 \mathrm{~m}$, the height of ring walling (from the level of the current ground surface) - 0.25-0.4 m, and width 0.5-1.5 m. Because the outer part (the tumulus ring) is located on a natural hill, its eastern and western parts slid down (Figure 1).

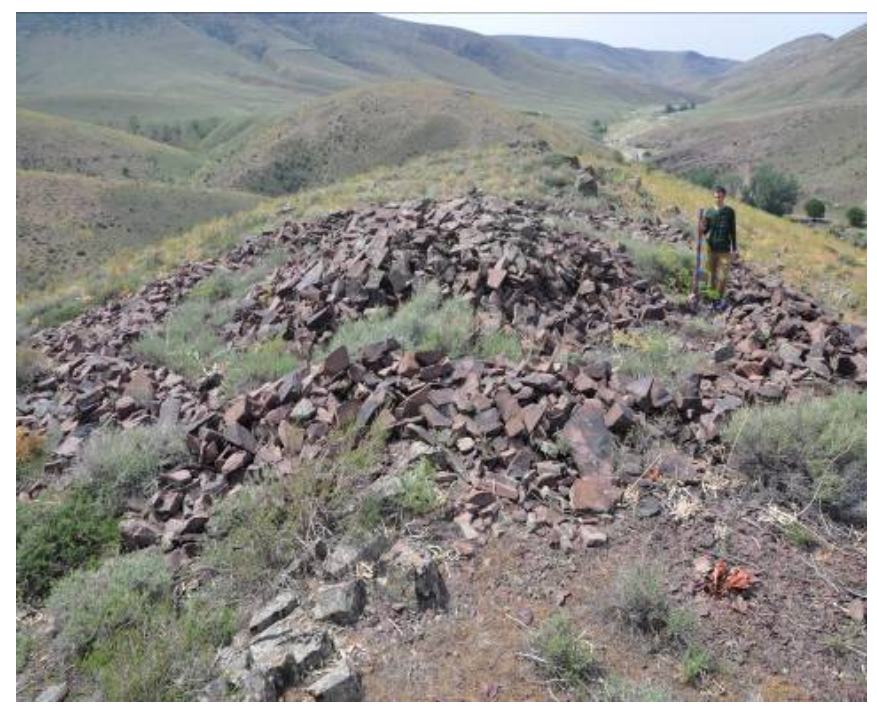

Figure 1. The burial ground Kyzylata I. Tumulus 4. General view from the north

The burial chamber of subrectangular form has the dimensions of $2.6 \times 1.0 \mathrm{~m}$, its longitudinal axis being oriented north-south (Figure 2-1). On the southern part the dromos joins to it. The inner part of the burial chamber is made by "false arching" technique having a ceiling of the large plates. Cross-section of the chamber is frustoconical. The width of the remaining part of the chamber ceiling is $0.5 \mathrm{~m}$. The length of the dromos part visually fixed from the surface $-1.2 \mathrm{~m}$, the width of the dromos at the entrance to the burial chamber is $0.6 \mathrm{~m}$. The major part of the dromos is littered with a small and medium-sized stones caught inside the structure as a result of the tumulus destruction, at the entrance part of the dromos a walling made using the "correct walling" technique and overlapping the entrance into tumulus was observed. The height of the remaining part of the tumulus walling is $0.48 \mathrm{~m}$; the length of the laid part is $0.7 \mathrm{~m}$. In the central and southern part of the burial chamber the upper crowns of walling, as well as the overlap of the chamber did not remain. Also the upper part of the dromos walling was lost.

The Tumulus is located $75 \mathrm{~m}$ north of the Tumulus 4, 540 meters to the north of Balakorgan fortress on the bridge of the saddle. As well as the Tumulus 4, the pad of the Tumulus 5 is contoured on perimeter by the annular bank (the so-called tumulus ring) built of small and medium stones. The proper walling wasn't observed in the ring structure. The dimensions of the ring (by outer contour) are $12 \times 13 \mathrm{~m}$. The width of the ring (not including the collapse) is about 1.0-1.5 m, the height of ring walling (from the level of the current ground surface) $-0.25-0.30 \mathrm{~m}$. The tumulus is built of stones of medium and large sizes (from $0.25 \times 0.1 \mathrm{~m}$ to $1.1 \times 0.9 \mathrm{~m}$ ). The dimensions of the tumulus itself are $7.5 \times 7.0 \mathrm{~m}$, and the maximum height of the remained part from the floor level of the burial chamber is $1.35 \mathrm{~m}$.

The burial chamber has an oval shape with dimensions of $2.3 \times 1.2 \mathrm{~m}$ oriented by the long axis along the northwest-southeast line. The dromos oriented according to the direction of the center line of the burial chamber is adjacent to the burial chamber in the southern part. The inner part of the burial chamber is made by "false arching" technique covered with the large plates. The cross-section of the chamber has a semi-oval shape - the width of chamber ceiling is $0.7 \mathrm{~m}$. The length of the dromos is $2.5 \mathrm{~m}$, the width of the dromos at the entrance to 
the burial chamber is $0.4 \mathrm{~m}$ and the width of the exit section of the dromos is $0.6 \mathrm{~m}$. The threshold of the dromos is framed by several large stones embedded in the walling foundation of the burial chamber. The width of the dromos threshold is $0.4 \mathrm{~m}$, the length $-0.3 \mathrm{~m}$, and the height of the threshold (from the floor level) $0.37 \mathrm{~m}$ (Figure 2-2).

The tumulus 6 is located $35 \mathrm{~m}$ north of tumulus 5 . The dimensions of the tumulus are $8.5 \times 8.0$, and taking into account the tumulus walling collapse $-9 \times 11 \mathrm{~m}$. The maximum height of the remained part (from the level of the current ground surface at the base of the northern floor of the tumulus) $-1.02 \mathrm{~m}$. The ring is missing. The so-called "gabion" made by the local shepherds nowadays is located at the top of the tumulus. The height of the "gabion" remains is $0.53 \mathrm{~m}$. The tumulus has not been excavated. A subrectangular deflection having the dimensions of $2.5 \times 1.8 \mathrm{~m}$ (depth is $0.3 \mathrm{~m}$ ) is located in the center of the mound at the place of the burial chamber.

The tumulus 7 is located $110 \mathrm{~m}$ north of tumulus 6, and 700 meters north of Balakorgan fortress, in a small saddle between the crest ridges. The dimensions of the tumulus are $12 \times 12 \mathrm{~m}$, taking into account the collapse of the burial mound structure $-12 \times 15 \mathrm{~m}$. The maximum height of the remained part from the floor level of the burial chamber is $1.35 \mathrm{~m}$. The ring is missing (Figure 2-3).

The burial chamber has subrectangular shape with the dimensions of $2.3 \times 1.4 \mathrm{~m}$, the dromos is adjacent to the burial chamber in the southern part. The longitudinal axis of the chamber is oriented along the northeast-southwest line. The inner part of the burial chamber is made by "false arching" technique. Cross-section of the chamber has semi-oval shape. The height of the burial chamber is $1.34 \mathrm{~m}$. The dromos was partially cleared - on the inner side within $0.5 \mathrm{~m}$. No traces of dromos made using "correct walling" were observed. The length of the dromos part visually fixed from the surface is $1.1 \mathrm{~m}$, the width of the dromos at the entrance to the burial chamber is $0.6 \mathrm{~m}$. The width of the dromos threshold is $0.6 \mathrm{~m}$, the length $-0.5 \mathrm{~m}$, the height of the threshold (from the floor level) is $0.3 \mathrm{~m}$.

The fragments of human bones, including the jaw of an adult, as well as fragments of pottery from - two stucco vessels were found in the northern part of the burial chamber at the floor level.

- Stucco vessel (Figure 3-1). Dimensions of the remained part: bottom diameter is $4.2 \mathrm{~cm}$, diameter of the largest part of the trunk is $8.0 \mathrm{~cm}$, neck diameter is $6.8 \mathrm{~cm}$, height of the remained part is $6.8 \mathrm{~cm}$, the height of the vessel to the widest part is $4.0 \mathrm{~cm}$, shoulder height is $2.6 \mathrm{~cm}$, wall thickness: $1.0 \mathrm{~cm}$ (bottom), $1.1 \mathrm{~cm}$ (near-bottom part), $0.7 \mathrm{~cm}$ (trunk), $0.5 \mathrm{~cm}$ (neck). The bottom is flat, without plate. The shape of the trunk is bomb-like. Judging by the small remained part, the neck had a small limb outwards. The forming: stucco. The burning is uneven - floor-standing. The surface of the walls is spotted, from pale red to gray-black. The forming is rough, the smoothing traces weren't observed. The traces of rough shaping with fingers were observed on the inner surface of the walls. The locking ring is missing.

- Fragment of the stucco vessel wall. The sizes of the remained part are $7.2 \times 4.7 \mathrm{~cm}$, wall thickness: from 0.7 to $0.6 \mathrm{~cm}$. The forming: stucco. The paste is of medium density, weth bad batter. The burning is uneven floor-standing. The outer surface has traces of rough coating with raw clay mortar, partially blackened using the vessel. The forming is rough, the smoothing traces weren't observed. The integrity is bad. A significant part of the vessel was lost.

In the course of the research on the tumulus of the burial ground Kyzylata I the material which allows specifying and significantly expanding our understanding of tumuluses as archaeological sites was obtained. The clothing material, as a whole, is also similar to ceramic complex, which can be found in tumulus burial grounds of Fergana (Litvinsky, 1973; Levina, 1971).

The burial ground Kyzylata II is located in the valley of a mountain stream Kyzylata, on its right bank, opposite the burial ground Kyzylata I. The burial ground occupies two low platforms above the riverbed on the spurs of the eastern slope of the ridge, which serves as a western border of Kyzylata Valley.

Total on the surface were registered 8 burial mounds (of 8 objects included in the described burial ground only 3 can be attributed to the type "Tumulus", the remaining burial mounds at the external examination of tumulus signs, i.e. the ground burial chamber and dromos were missing, or not remained) of various diameters and heights. The burial mounds in the burial ground are located in two groups, the natural border between which is a small hollow between two branches of the ridge. The average distance between tumuluses is $100 \mathrm{~m}$.

The Tumulus 1 occupies the extreme south-west position on the territory of the burial ground. The floodplain area on which the tumulus is located has a strong bias towards the east, which is why most part of the structure collapse is located on the eastern part of the building. The dimensions of the tumulus are $12 \times 12 \mathrm{~m}$, taking into 
account the collapse of the burial mound structure - $14 \times 16 \mathrm{~m}$. The maximum height of the remained part from the floor level of the burial chamber is $1.55 \mathrm{~m}$. The ring is missing. The burial chamber has an oval shape with the dimensions of $2.3 \times 1.63 \mathrm{~m}$ (Figure 2 - 4). The inner part of the burial chamber is made by "false arching" technique. Cross-section of the chamber has a semi-oval shape. The height of the burial chamber is $1.3 \mathrm{~m}$. The dromos has been cleared. The length of the studied part of the dromos is $1.1 \mathrm{~m}$. The width of the dromos is $0.6 \mathrm{~m}$, the total length is about $1.7 \mathrm{~m}$. At the threshold the dromos has an evident widening - up to $0.8 \mathrm{~m}$; threshold height (from the floor) is $0.15 \mathrm{~m}$ ( $0.03 \mathrm{~m}$ above the level of the cleared findings).

The fragments of human bones as well as fragments of pottery from three molded vessels were found in the northern part of the burial chamber at the floor level.

- Stucco vessel (Figure 3-2). Dimensions of the remained part: bottom diameter is $7.2 \mathrm{~cm}$, diameter of the largest part of the trunk is $9.3 \mathrm{~cm}$, neck diameter $6.9 \mathrm{~cm}$. Total height of the vessel is $10.7 \mathrm{~cm}$, neck height is 1.25 , the height of the vessel to the widest part is $6.0 \mathrm{~cm}$, shoulder height is $3.45 \mathrm{~cm}$, wall thickness $1.05 \mathrm{~cm}$ (bottom), 1.1 $\mathrm{cm}$ (near-bottom part), $0.9 \mathrm{~cm}$ (trunk), $0.7 \mathrm{~cm}$ (neck and crown). The handle is bonded and is oval in cross section (the length is approx. $4.5 \mathrm{~cm}$, thickness $-1.2 \mathrm{~cm}$, width -1.8 ). The bottom is flat at roughly decorated straight disc-shaped pan. The crown is well profiled and curved outwards. The forming is molded. The burning is uneven - floor-standing. The traces of rough shaping with fingers were observed on the inner surface of the walls. A part of the vessel was lost. The archaeological integrity of the vessel is broken only by uncertainty of the exact place of handle attachment to the trunk.

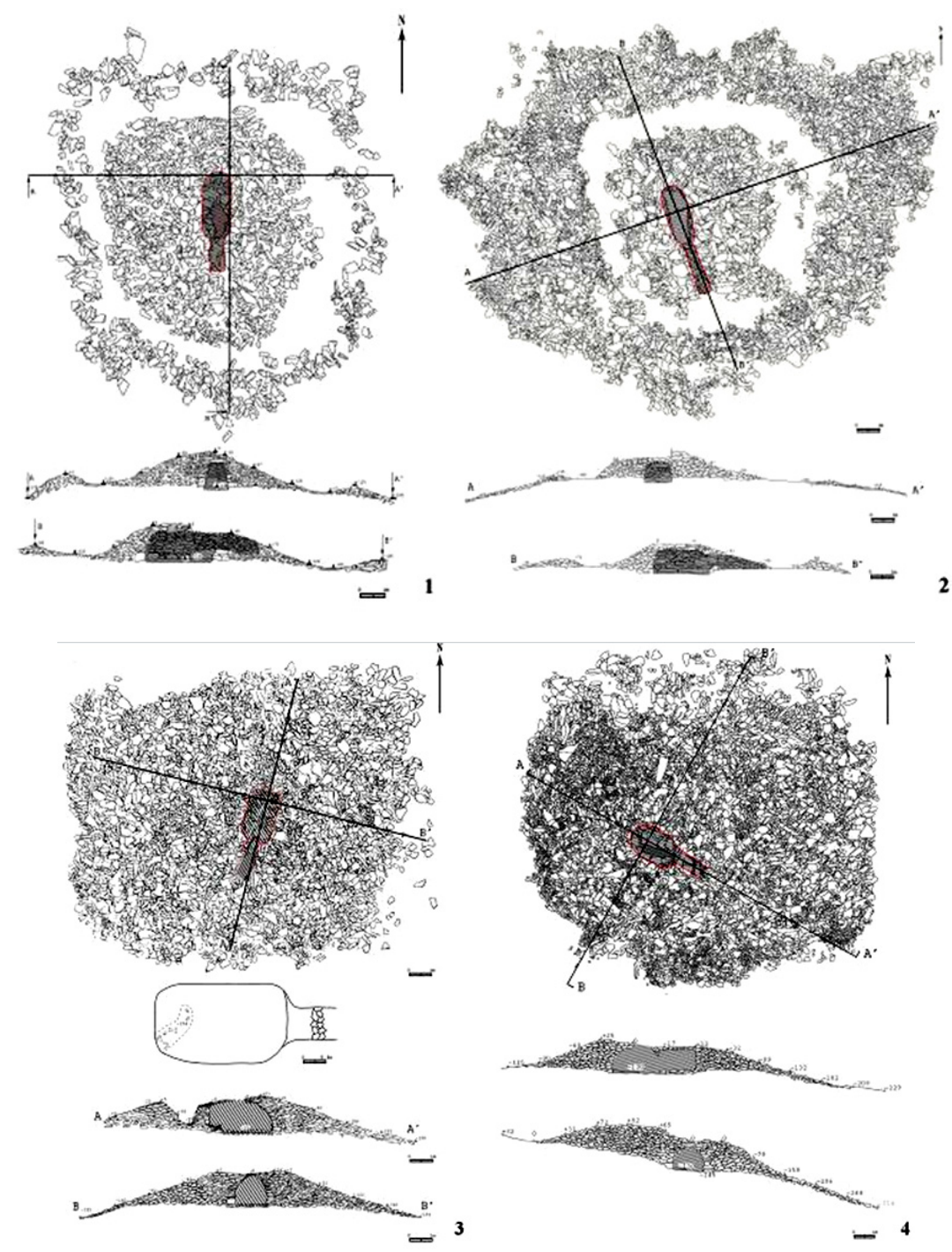

Figure 2. The burial ground Kyzylata I-II. Plans, cuttings

1 - Kyzylata I. Tumulus 4; 2 - Kyzylata I. Tumulus 5; 3 - Kyzylata I. Tumulus 7; 4 - Kyzylata II. Tumulus 1 


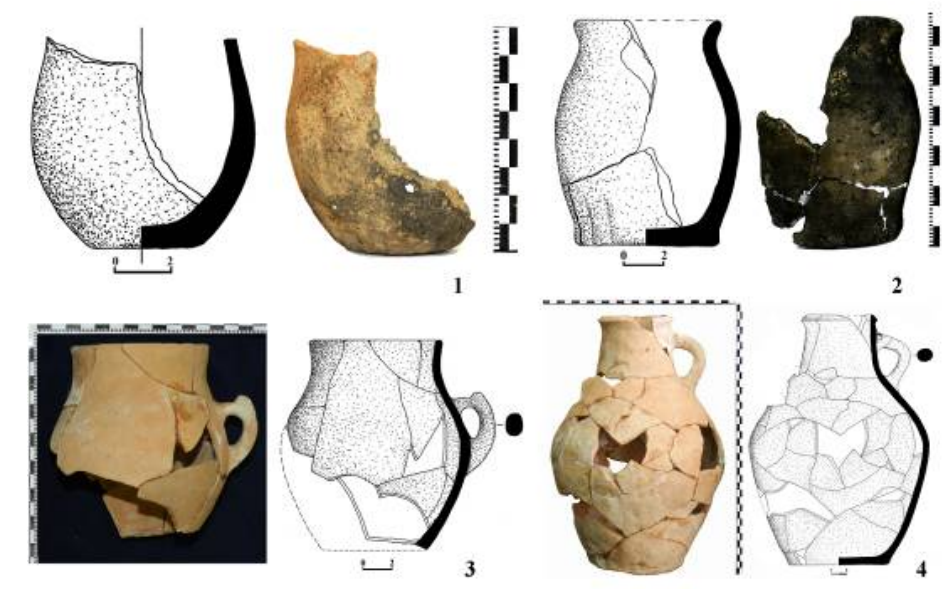

Figure 3. Finds

1 - The burial ground Kyzylata I. Tumulus 7. Fragment of stucco vessel; 2 - The burial ground Kyzylata II. Tumulus 1; 3 - Fragments of vessels; Vessel 1; 4 - The burial ground Biresek I. Tumulus 12. Vessel 2

- Bottom, crown and fragments of walls of a large vessel (khumcha). Dimensions: bottom diameter $24.5 \mathrm{~cm}$, maximum diameter along the trunk $39 \mathrm{~cm}$, diameter of the remained part of the neck $20 \mathrm{~cm}$; maximum height of the remained part $42 \mathrm{~cm}$, wall thickness: $0.8 \mathrm{~cm}$ (trunk), $0.75 \mathrm{~cm}$ (remained part of the upper part of the shoulder - transition to the neck), $0.9 \mathrm{~cm}$ (near-bottom part), $1.05 \mathrm{~cm}$ (bottom), $1.4 \mathrm{~cm}$ (crown), $0.9 \mathrm{~cm}$ (neck). The bottom is flat, without plate. The crown is well profiled and curved outwards. The forming: stucco. The burning is uniform. The scratches were found on the surface at the smoothing down the surface with the chip. Engobed coating. A painting in the form of streaks of red and yellow engobe on a gray background is in the outer surface.

- Crown and a portion of the vessel wall. Fragment $(6.0 \times 4.7 \mathrm{~cm})$. Dimensions: entrance diameter $12.0 \mathrm{~cm}$, neck diameter $11.5 \mathrm{~cm}$, the maximum diameter of the remained part of the trunk $14.7 \mathrm{~cm}$. The maximum height of the remained part $5.1 \mathrm{~cm}$, neck height $2.1 \mathrm{~cm}$; wall thickness: $0.6 \mathrm{~cm}$ (trunk), $0.7 \mathrm{~cm}$ (neck) 0.5-0.6 cm (crown), 0.9 $\mathrm{cm}$ (neck). The crown is well profiled and slightly curved outwards. The forming: stucco. The burning is uniform. The vessel is covered with orange engobe of poor quality. The traces of paining with dark brown engobe on orange background are widely scattered. A significant part of the vessel was lost.

The tumulus burial ground Biresek I is situated in Turkestan, region of South Kazakhstan, $11 \mathrm{~km}$ to the north north-east of the city Kentau, in the Valley of Biresek River, $500 \mathrm{~m}$ to the south-west of Karatau reserve cordon. The tumuluses are located on the right bank of Biresek on the slope of the ridge delimiting the narrow valley of the river from the northwest.

The monument was unveiled in 2012, by the Karatau team of Syganak archaeological expedition (S. Murgabaev, M. Bahtybaev) (Report, 2012). Totally 17 tulumuses of different diameter and height were recorded in the burial ground.

Tumulus 5 is located on the ridge slope delimiting the Valley of the Biresek River from the west, occupying a small area at the base of a large rock outcrop. The eastern part of the site, on which the base of tumulus is situated, is reinforced with the walling of large raw slabs. Dimensions of the tumulus are $8.0 \times 9.0 \mathrm{~m}$. The maximum height of the remained part from the floor level of the burial chamber is $1.61 \mathrm{~m}$. A large amount of gravel with sand and small stones is observed in the tumulus walling as well as in the filling of the burial chamber.

The burial chamber is of subrectangular shape with the dimensions of $2.33 \times 1.63 \mathrm{~m}$ (Fig. (4 - 1)). The inner part of the burial chamber is made by "false arching" technique. The length of the dromos is $1.75 \mathrm{~m}$, the width of the dromos at the entrance to the burial chamber is $0.6 \mathrm{~m}$ and the width of the exit section of the dromos is $0.67 \mathrm{~m}$. The threshold is marked with a large flat stone of sub-triangular shape. The width of the dromos threshold is 0.5 $\mathrm{m}$, the length $-0.45 \mathrm{~m}$, and the height of the threshold (from the floor level) $-0.19 \mathrm{~m}$ (-134 from the conditional "0"). The bottom of the burial chamber is a surface of indigenous rocky outcrop. The bottom has a significant slope to the east (-0.2-0.25 m). The threshold level is at an altitude of western corners of the burial chamber. At the beginning of excavation the dromos of tumulus was correctly walled using raw flat stones of medium size $(0.4 \times 0.3 \mathrm{~m})$. At the break-up of the walling it turned out that the top crowns of the walling are wedged by small 
stones $(0.1 \mathrm{~m} 0.15 \mathrm{~m})$, triangular in shape, and it was noted that the "wedges" were driven into the walling from the inside of the burial chamber.

The findings in tumulus 5 include only a thin string bead which was found in the southeastern part of the burial chamber at floor level.

The bead. It has an elongated cylindrical shape, noticeable bend, and it is round in cross section. Dimensions: length $1.4 \mathrm{~cm}$, thickness (sectional diameter) $0.4 \mathrm{~cm}$; diameter of the hole $0.04 \mathrm{~cm}$. The bead is of white color. The longitudinal threadlike veins are distinguishable. In contact with water the bead becomes pale pink.

Tumulus 12 has dimensions of $7.5 \times 7.0 \mathrm{~m}$. The maximum height of the remained part from the floor level of the burial chamber: $1.86 \mathrm{~m}$. The ring is missing. The tumulus was built on rocky ground specially aligned for the purpose by the walling of large slabs. The burial chamber has a subrectangular shape with the dimensions of $2.34 \times 1.60 \mathrm{~m}$ (longitudinal walls of 2.18 and $2.34 \mathrm{~m}$, cross walls 1.69 and $1.43 \mathrm{~m}$ ). The floor of the burial chamber is fixed at a depth of «-131» from the conditional «0». The inner part of the burial chamber is made by "false arching" technique. Cross-section of the chamber has a semi-oval shape. The dromos is facing southeast. The length of the dromos - $1.4 \mathrm{~m}$, the width of the dromos at the entrance to the burial chamber is $0.6 \mathrm{~m}$. The height of the dromos from threshold to ceiling is $1.24 \mathrm{~m}$. In section the dromos has the shape of an equilateral triangle. Threshold level of the dromos ("-119" from the conditional "0") rises above the floor of the burial chamber by $0.15 \mathrm{~m}$ (Figure 4-2).

The findings are exhausted by three stucco vessels, metal belt buckle, as well as tin plate.

- Stucco vessel. Dimensions: bottom diameter $7.0 \mathrm{~cm}$, diameter by rib $13.5 \mathrm{~cm}$, neck diameter $9.0 \mathrm{~cm}$, entrance diameter $9.5 \mathrm{~cm}$ (Figure 3-3). The total height of the vessel is approx. $14.5 \mathrm{~cm}$, neck height $3.2 \mathrm{~cm}$, rib height 7.5 $\mathrm{cm}$; wall thickness: $0.55 \mathrm{~cm}$ (neck and crown) and $0.6 \mathrm{~cm}$ (trunk), 0.7 (near-bottom part). Handle in section - a rectangle with rounded corners. Handle length: $4.8 \mathrm{~cm}$, width $1.4 \mathrm{~cm}$, thickness $1.1 \mathrm{~cm}$. In the upper part of the handle there is a characteristic V-shaped protome. The bottom is flat, without plate. The neck is straight; the crown is slightly bent outwards. The near-bottom part of the vessel expands to the top, smoothly passing to gradual shoulders. It was made of good paste, the mix is qualitative, and the pottery fragment is tight. The surface is light brown.

- Stucco vessel. Dimensions: bottom diameter $-13.0 \mathrm{~cm}$, diameter by rib $-23.5 \mathrm{~cm}$, neck base diameter $-10.4 \mathrm{~cm}$, diameter of the neck top $-9.0 \mathrm{~cm}$, entrance diameter $-10.5 \mathrm{~cm}$. Total height of the vessel is $33.5 \mathrm{~cm}$, neck height $-8.0 \mathrm{~cm}$, rib height $-15.5 \mathrm{~cm}$; wall thickness $-0.8 \mathrm{~cm}$ (neck), the wall thickness of the trunk is not the same from 0.75 to $0.9 \mathrm{~cm}$ (trunk), $0.8-0.9 \mathrm{~cm}$ (bottom). Handle in section - a rectangle with rounded corners. Handle length: $8.5 \mathrm{~cm}$, width $1.65 \mathrm{~cm}$, thickness $1.6 \mathrm{~cm}$. In the upper part the handle has two characteristic $\mathrm{V}$-shaped protomes (Figure 3 - 4). The bottom is flat, without plate. The neck is conical - tapered upwards. The crown is rectangular with clearly defined edges, bent outward. The bottom part of the vessel is directly conically expanding towards the top, with a noticeably sharp bend, passing to gradual tapered shoulders. The transition from the neck to the shoulders is also clearly indicated by a sharp change in the angle as well as in some areas by stipples on the outer wall surface. The vessel has a nose at the base of the neck that has been preserved in the traces. The surface is light brown. No ornamentation.

- Stucco vessel. Dimensions: bottom diameter $-9.0 \mathrm{~cm}$, diameter by rib $-13.5 \mathrm{~cm}$, neck diameter $-9.0 \mathrm{~cm}$, entrance diameter $-11.0 \mathrm{~cm}$. Total height of the vessel is $17.0 \mathrm{~cm}$, neck height -4.8 , rib height $-6.0 \mathrm{~cm}$; wall thickness - $0.55 \mathrm{~cm}$ (neck), $0.6 \mathrm{~cm}$ (crown), $0.7-0.8 \mathrm{~cm}$ (trunk), 1.1 (near-bottom part). Handle in section - a rectangle with rounded corners. Handle length: $5.6 \mathrm{~cm}$, width $1.8 \mathrm{~cm}$, thickness $1.35 \mathrm{~cm}$. At the top the handle has a characteristic V-shaped form. The bottom is flat, without plate. The neck is high, slightly bent outwards by trumpet. The crown is well profiled and curved outwards. The trunk is bomb-like. The near-bottom part of the vessel expands to the top, smoothly passing to sharp shoulders. The surface is red. Hand molding, the outer surface is roughly smoothed by hand; the fingerprints are visible in some places.

- Iron buckle Dimensions: front metal plate $-4.3 \times 3.5 \mathrm{~cm}$ (thickness $0.4 \mathrm{~cm}$ ). The forged pattern on the front side - in a rectangle frame two circles with touching edges, with inscribed rhombic shapes are situated. By outer edge of the metal plate there is a pattern supplemented with three pyramidal teeth formed from three welded rings (diameter $0.7 \mathrm{~cm}$ ) are soldered to the edge, so that the metal plate takes the form of reduced plaque trident. The metal plate is attached to the buckle by two rivets (section diameter $0.3 \mathrm{~cm}$ ), which were also fixed. The clamp of the buckle is an iron plate bent into a loop with a slot for the prong and the opening for the buckle ring. The remaining long ends of the plate are attached to the rear plate from the face. The total length of the plate is approx. $8.3 \mathrm{~cm}$ (in the retracted position $-4.2 \mathrm{~cm}$ ), thickness $-0.2 \mathrm{~cm}$, width of the prong slot $-1.1 \mathrm{~cm}$. The ring belt has a shape of a regular oval (dimensions $2.2 \times 3.1 \mathrm{~cm}$ ); it is made of a rod triangular in cross-section and 
expanding to the middle $(1.0 \times 0.7 \mathrm{~cm})$ and tapered at the ends $(0.7 \times 0.45)$. The prong is made of rod triangular in cross-section with the enforcement rib facing the front side of the buckle. The tip of the prong is bent inwardly at an angle of $90^{\circ}$. The prong joint has two specially provided lockers, restricting free stroke of the buckle prong and turning it into a hard belt lock. The prong length is $2.7 \mathrm{~cm}$, cross-section: $0.6 \mathrm{x} 0.4 \mathrm{~cm}$.

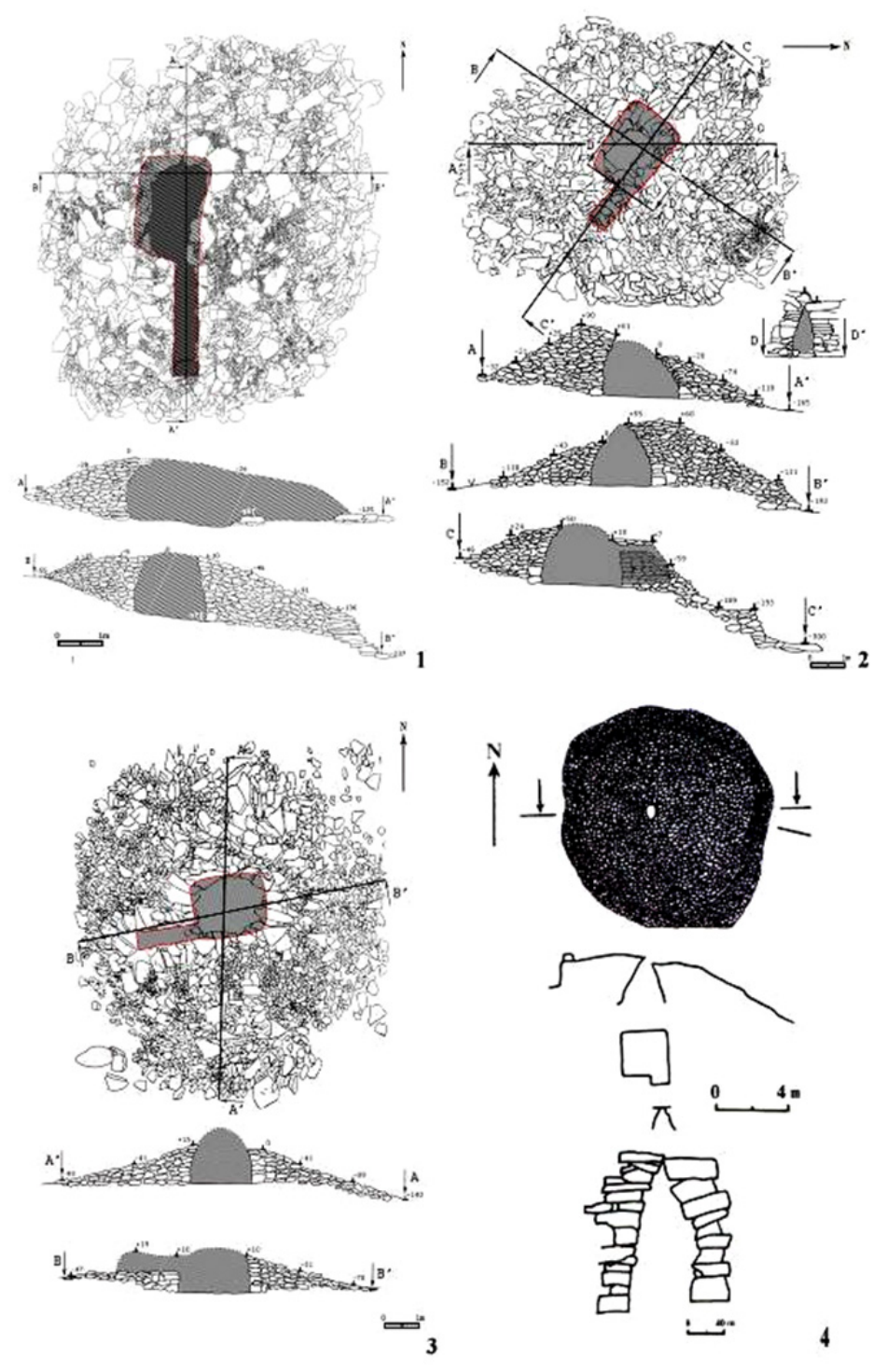

Figure 4. Plans, cuttings

1 - The burial ground Biresek I. Tumulus 5; 2 - The burial ground Biresek I. Tumulus 12; 3 - The Tumulus Biresek II; 4 - The burial ground Esekbel. Tumulus 1

- Fragment of the iron fastening. It is an iron plate folded in half with the dimensions of $5.2 \times 1.2 \mathrm{~cm}$ (folded $2.6 \times 1.2 \mathrm{~cm}$ ). The plate thickness is $0.07 \mathrm{~cm}$, the ends put together tare pierced through with a small iron nail, serving as a rivet. Apparently, the plate has been serving as fixing for something on leather.

The single tumulus Biresek II is situated in Turkestan, region of South Kazakhstan, $11 \mathrm{~km}$ to the north north-east of the city Kentau, in the Valley of Biresek River, $600 \mathrm{~m}$ to the south-west of Karatau reserve cordon. The tumulus is located on the left bank of Biresek on the slope of the ridge delimiting the narrow valley from the south-east.

The monument was unveiled in 2012, by Karatau team of Syganak archaeological expedition (S.Murgabaev, M.Bakhtybaev) (Report, 2012). 
Dimensions of the tumulus are $8.5 \times 8.0 \mathrm{~m}$. The maximum height of the remained part from the floor level of the burial chamber is $1.05 \mathrm{~m}$ (Figure 4-3). The burial chamber has a subrectangular shape with the dimensions of $2.07 \times 1.75 \mathrm{~m}$ (longitudinal walls of 2.01 and $1.63 \mathrm{~m}$, cross walls 1.38 and $1.52 \mathrm{~m}$ ). The floor of the burial chamber is fixed at a depth "-96" from the conditional " 0 ". Cross-section of the chamber has a semi-oval shape. The tumulus dromos faces west. Dromos length $-1.7 \mathrm{~m}$, width $-0.6 \mathrm{~m}$.

The fragment of the handle and a wall portion of a pottery vessel. Dimensions: wall thickness $0.35 \mathrm{~cm}$. The handle has a shape of a flattened oval in cross-section, with the dimensions of $4.7 \times 1.8 \mathrm{~cm}$. It was made of good paste, the mix is qualitative, and the pottery fragment is tight. No impurities in the mix. The pottery fragment in break is of brick-red color. It is uniformly calcined. The burning is qualitative, oxidative. The surface of the pottery fragment is light red. The forming was made on the potter's wheel. The vessel is covered with a light yellow engobe and the ornament in the form of vertical streaks of red engobe on light yellow background.

\section{Discussion}

In 2004, the Turan archaeological expedition excavated a tumulus 1 of the burial ground Esekbel upstream the Biresek River. The tumulus has the diameter of $15 \mathrm{~m}$ and the height of $2.2 \mathrm{~m}$ (Figure 5). According to the construction the tumulus is similar to the described above, but the outer contours of the walling were preserved well, but the burial chamber was preserved in a subsquare shape (Figure 4-4). Two gold products intended for embroidery were discovered at the clearing of the burial chamber. One of them depicts the head of a feline predator; the other is leaf-shaped (Figure 6) (Report, 2005; Arynov, 2005).

In 1958, 1962, 1969 in the course of archaeological research in our area the tumuluses and burial chambers similar in construction to our tumuluses were excavated, and unlike ours they do not have dromoses. The burial chamber is elongated from north to south; the floor of the burial chamber was cleared and paved with stone slabs (Mershiev, 1962; Maksimova, 1973). Most part of the tumuluses found by the authors in the course of exploration in different years since 1998 in the central and northern part of Karatau has dromos structures. (Report, 2005). The burial structures with dromos are practiced from the Late Bronze Age (Itina \& Yablonsky, 1997). All tumuluses with dromos examined in 2012 and burial chambers in most are elongated from north to south, sometimes due to the mountainous topography they are oriented to the east. From this we can conclude that there was not a certain strict orientation. The next feature is a stone fence around the mound in Kyzylata I group (Figure 1). Such stone fences of various types can be found in the graves of the Bronze Age, early Iron Age and the Middle Ages (Nurmaganbetov, 2011; Goryachev, 2011; Aitkali et al., 2014; Report, 2013). And in some Fergana mounds the fences were laid in rows of large stones around the mound and the space between them was filled with small stones (Litvinsky, 1973).

Judging by the bone material the legs of the buried are oriented to the corridor. Tumuluses have surface structures and there is no burial chamber inside them. The tradition of burial in Tumulus allows to confidently say that the buried have not been covered with earth. The floor of the burial chambers in Tumuluses excavated by A.G.Maksimova is paved with stone slabs, there were observed very small amounts of the bone material or it does not exist at all, apparently, because the buried were lying on the surface. Or the "dead" was buried after complete or partial burning, or was buried only as a skeleton. The tradition of skeleton burial after the "dead" was given to be devoured by birds, dogs, exist in some cultures to the present day. Probably, tumuluses were used for burial not once, but this is still a hypothesis.

The anthropological material has confirmed the interpretation of tumuluses as burial sites, with the burial rite in many respects similar to that in the tumuluses of the western Fergana (Litvinsky, 1959). The close parallels to Fergana analogs does exist (size, shape, walling technology, the presence of dromoses and rings and etc.) in the architecture of the studied monuments of Karatau, and in the topography of their placement (mountain slopes and passes). The clothing material found in the tumulus of Kyzylata and Biresek georges and, in general, is also similar to the ceramic complex that is found in the tumulus burial grounds of the Western Fergana (Litvinsky, 1973), the ceramic complex of the middle and lower reaches of Syr Darya, including Otrar oasis (Levina, 1971).

In the analysis of the tumulus complexes from tumuluses of the Western Fergana, taking into account all categories of inventory, the researchers divide them into two groups: western and eastern. The Western Group is considered as a mining option of Kaunchi-Jon culture. The eastern group is characterized by tradition of late-usun and plain Fergana. All materials are dated starting from I-II centuries BC to VI-VII centuries. But at the same time the proportion of burials dates back to the V-VII centuries. (Litvinsky, 1972) M.E. Voronets dated tumuluses by the I-II centuries AD (Voronets, 1954), B. A. Litvinsky reviewing these materials dated them to the IV-V centuries. (Litvinsky, 1954) A. G. Maksimova dates the materials from tumuluses of Karatau Ridge by the first half of the I millennium (Maksimova, 1973). 


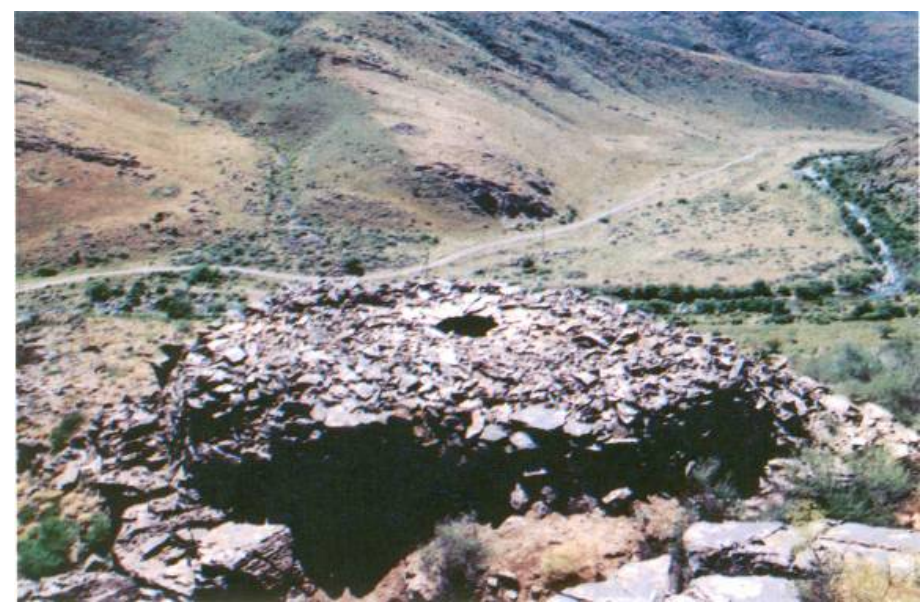

Figure 5. The burial ground Esekbel. Tumulus 1. General form

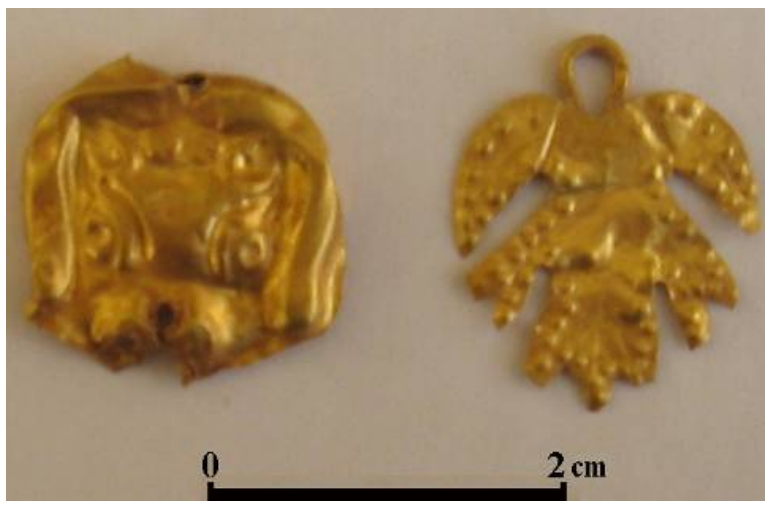

Figure 6. The burial ground Esekbel. Tumulus 1. Finds

\section{Conclusion}

Unlike ceramics from the Fergana tumuluses in the region under consideration, the ceramics with zoomorphic handle has not been found, but nevertheless more recent versions with protomai at the top of the handle can be met. Generally, in the first half of the I millennium the zoomorphic images on the handles of ceramic vessels in Central Asia, especially in the middle reaches of Syr Darya, are replaced by conventional Protomai and later, in 7 th century they are extremely rare. The ceramics of pre-Syr-Darya Karatau under consideration can be dated to IV-VII centuries. Among the ceramic complex of 2012, only a single exemplar made on a potter's wheel, with traces of light yellow engobe with streaks of red engobe (Biresek II), has a broad chronological framework, covering more recent periods. This feature pushes us to think about reuse of tumuluses.

Among metal products 2 small belt buckles from Kyzylata burial ground, especially one with a forged pattern on the front side, were widely spread in the VI-VIII centuries. It is difficult to draw a clear analogy to gold products found in 2004 in the Esekbel burial ground, but the plate with the head of predator turned full face is stylistically reminiscent to Hun products. A leaf-shaped article with a clasp at the top, in terms of its time, is similar to the time of the plate. We assume that the chronological framework of the metal products is similar to the ceramic complex.

Finally, the topography of the burial ground Kyzylata I, clearly linking the burial to one historical and cultural complex with a medieval fortress Balakorgan, allows to approach the question of settlement monuments left by population that practiced burial rites in tumuluses.

These results are preliminary. Future research on the monuments would extend the chronological framework and will allow resolving the issues of ethnicity.

\section{References}

Aitkali, A. K., Zhuniskhanov, A. S., Kairmaganbetov, A. M., Ahmetov, M. G., \& Rakhmankulov, E. Z. (2014). Preliminary results of a study in the Karatobe burial ground in the microarcheological area of Kokentau in 
2014 (pp. 151-160). In the Proceedings of the IV International Scientific Conference «Kadyrbay Readings -2014», Astana.

Arynov, K. (2005). Archaeological sites in the riverbed of Biresek and Kyzylata (pp. 48-49). Turkestan: Scientific collection "Young Scientist".

Goryachev, A. A. (2011). Archaeological research of park and burial ground and the tumulus of early Iron Age in the upper reaches of Turgen. Margulan readings-2011 (pp. 227-231). In the Proceedings of the International Archaeological Conference, Astana.

Itina, M. A., \& Yablonskiy, L. T. (1997). Saki of lower Syr Darya (p. 187). Moscow: ROSSPEN.

Levina, L. M. (1971). The pottery of lower and middle Syr Darya in the I millennium BC. table.122,124,128. table. 46,8; table.48,1 (p. 236). Moscow: Nauka.

Litvinskiy, B. A. (1959). Study of tulumuses of the northeastern part of Leninabad region in 1957. Archaeological work in Tajikistan in 1957, V, 123, fig.7.

Litvinskiy, B. A. (1965). Central Asian iron arrowheads. CA, 2, 85.

Litvinskiy, B. A. (1972). Tumuluses and burial mounds of Western Fergana (Excavations. Funeral rites in the light of Ethnography). Moscow: Nauka.

Litvinskiy, B. A. (1973). Ceramics from western Fergana burial grounds (first millennium BC). table 46,11; table .48,1; table. 56,4. Moscow: Nauka.

Maksimova, A. G. (1973). Tumuluses of Karatau Ridge. Archaeological Research in Kazakhstan (pp.156-165). Almaty: Nauka.

Merishev, M. S. (1962). Burial in Aktobe settlement. Proceedings of IIAE in the Kazakh SSR (Vol. 14, pp.84-87). Almaty: Archeology.

Nurmaganbetov, E. M. (2011). New archaeological research sites Ostrava on the island Tasaral, Lake Balkhash. read Margulan readings 2011 (pp. 317-320). In the Proceedings of the International Archaeological Conference, Astana.

Report of the Turan archaeological expedition of the research work following the results of 2004 on the topic Research in the South Kazakhstan region (intermediate). Turkestan, 2005. pp. 192. Archive of Research Center of Archaeology, Inv. 4, 212, 70-72.

Report on the research work at the end of 2012 made under the budget program of MES RK 055 "scientific and / or technical activity", subprogramme 101 "grant funding for research", by priority the "intellectual potential of the country", by subpriority " the fundamental and applied research in the field of economic, social and human sciences" on the topic "Continuity of ancient and medieval archaeological sites of the southern slopes of Karatau (intermediate). - Turkestan, 2012. p. 141. Archive of Research Center of Archaeology, Inv. 15,78 .

Report on the research work at the end of 2013 made under the budget program of MES RK 055 "scientific and / or technical activity", subprogramme 101 "grant funding for research", by priority the "intellectual potential of the country", by subpriority " the fundamental and applied research in the field of economic, social and human sciences" on the topic "Continuity of ancient and medieval archaeological sites of the southern slopes of Karatau (intermediate). - Turkestan, 2013. - p. 96. Archive of Research Center of Archaeology, Inv. 16, 68-77.

Voronets, M. E. (1954). Archaeological research of the Institute of History and Archaeology and the History Museum of the Academy of Sciences of Uzb.SSR on the territory of Fergana in 1950-1951 years. Proc. on the territory of Fergana in 1950-1951 (pp. 63-77). Works of the History Museum of Uzb.SSR, red. II. Tashkent.

\section{Copyrights}

Copyright for this article is retained by the author(s), with first publication rights granted to the journal.

This is an open-access article distributed under the terms and conditions of the Creative Commons Attribution license (http://creativecommons.org/licenses/by/3.0/). 